\title{
Increasing Inequality, Consumer Credit and Financial Fragility in an Agent Based Macroeconomic Model
}

\author{
Alberto Russo*1, Luca Riccetti $^{2}$, and Mauro Gallegati ${ }^{1}$ \\ ${ }^{1}$ Università Politecnica delle Marche, Ancona, Italy \\ ${ }^{2}$ Sapienza Università di Roma, Roma, Italy
}

\begin{abstract}
We investigate the interplay between increasing inequality and consumer credit in a complex macroeconomic system with financially fragile heterogeneous households, firms and banks. Simulation results show that there are pros and cons of introducing consumer credit: on the one hand, for a certain time, it leads to lower unemployment through boosting aggregate demand; on the other hand, it accelerates the system tendency to the crisis. Since the increase of financial profits goes with a decline of households' real wealth, a policy trade-off emerges.
\end{abstract}

Keywords: consumer credit, inequality, agent-based macroeconomics, business cycle, profit rate, crisis, unemployment.

JEL classification codes: C63, D31, E21, E32.

Acknowledgments and compliance with ethical rules: We are very grateful to the participants at EMAEE2013 held at the SKEMA Business School, Sophia Antipolis, Nice (France), on June 10-12, 2013, for useful comments and suggestions. We are indebted to two anonymous referees for valuable comments and suggestions. The authors declare that they have no conflict of interest. The research does not involve human participants and/or animals.

\footnotetext{
${ }^{*}$ Corresponding author: Department of Economics and Social Sciences, Università Politecnica delle Marche, Piazzale Martelli 8, 60121 Ancona (Italy). E-mail: alberto.russo@univpm.it
} 


\section{Introduction}

One of the elements that the present crisis and that of the 1930s have in common is the increase of inequality that preceded the financial collapse of both eras. Indeed, many advanced economies experimented a rise of both income and wealth inequality in recent decades (IMF, 2007; Atkinson et al. 2011; OECD, 2011). In particular, income inequality was relatively low and roughly stable during the 1960s and 1970s, then it drastically increased, from the 1980s onward, to levels comparable to those of the 1920s (van Treeck, 2009). Accordingly, rising inequality could be at the root of the present crisis, as well as the "bad distribution of income" that was one of the major causes of Great Crash of 1929 and of the Great Depression (Galbraith, 1959).

The rise of inequality may affect macroeconomic evolution: for instance, if consumption grows less than proportionally with wealth, that is, if the rich consume relatively less with respect to wealth than the poor, then increasing inequality may result in insufficient aggregate demand. In a monetary production economy such as the capitalist system, this may lower the profit rate, possibly resulting in lower investments and then more unemployment. Actually, consumer credit and other forms of indebtedness can prevent this from happening for a while, but at the cost of a growing financial instability that may increase the likelihood of a larger unemployment crisis.

As noted by Perugini et al. (2013), a central question is whether high or rising inequality contributed to the accumulation of unsustainable debt which, in turn, is widely recognized as being a driver to episodes of financial instability. According to the authors, the latter notion can be traced back to Irving Fisher who argued that all great booms and depressions are due to "over indebtedness to start with and deflation following soon after" (Fisher, 1933, p. 341). Along these lines, Minsky (1982) developed a theory of "financial fragility", which explains how the seeds of financial instability are sowed during the expansionary phase: when firms' profits are high, investment rises based on more borrowing that can be repaid using cash flows (hedge financial position), until cash flow is not enough to repay the debt (speculative position) and even interest (Ponzi or ultra-speculative position), and eventually the system collapses. In a historical perspective, the Minskian model is useful in describing a secular sequence of "manias, panics and crashes" (Kindleberger and Balibar, 2005). Consumer credit and other forms of household finance enlarge the credit supply to the private sector. Based on an econometric analysis of 18 OECD countries covering the period 1970-2007, ${ }^{1}$ Perugini et al. (2013) find a significant, direct, positive relationship between income concentration and private sector indebtedness. Moreover, they show that private sector indebtedness may increase the probability of financial crises.

As for the US, Fazzari and Cynamon (2013) find that, disaggregating household spending,

\footnotetext{
${ }^{1}$ The dependent variable in all model specifications is the level of domestic credit to the private sector. Data are from the World Development Indicators database
} 
income and saving between the top $5 \%$ and the bottom $95 \%$ of the income distribution, the top $5 \%$ did indeed spend a smaller share of income, but the "demand drag" did not occur due to the rise of the spending share of the bottom $95 \%$, accompanied by a decline of their saving rate and by a historic increase in borrowing. Moreover, they find that the unsustainable rise in household debt was concentrated in the bottom $95 \%$ as their income share declined. "The coincidence of rising income inequality and increasing access to credit provided the impetus for a debt-led consumption booms" (Fazzari and Cynamon, 2013, p.11). But the increase of household leverage led to more financial fragility and eventually the system crashed in 2007-8.

Barba and Pivetti (2009) identify similar trends when analyzing the evolution of household debt in the US. They stress that, differently from interpretations of the phenomenon based on the life-cycle hypothesis or in terms of erratic deviations of current income flows from their long-run trend, rising household debt is the result of persistent changes in income distribution and growing income inequalities. As a consequence of rising household debt, low wages seem to be consistent with relatively high levels of aggregate demand, thus providing the solution to the contradiction between the necessity of high and rising consumption levels (for the growth of the system's actual output), and the conditions of distribution which keeps within limits the real income of the vast majority of society.

Kumhof and Ranciere (2010) built a theoretical model that links inequality, household debt and financial crises. In particular, they study how high leverage and crises can arise as a result of changes in the income distribution. From an empirical point of view, indeed, the periods 1920-1929 and 1983-2008 both exhibited a large increase in the income share of the rich, a large increase in leverage for the remainder, and an eventual financial and real crisis. The authors show that these features arise endogenously as a result of a shift in bargaining powers over incomes. ${ }^{2}$ Related to the shift of bargaining power and changes in income distribution, there are the macroeconomic consequences of a persistent deviation of wage growth from productivity growth, as noted by Palley (2012) and Setterfield (2012). ${ }^{3}$

All in all, there seem to be causal links between rising inequality and the expansion of finance, and between unsustainable indebtedness and financial crises. There could be, then, a significant impact of inequality on financial instability and macroeconomics dynamics. This is particularly relevant to understanding the causes of the current crisis.

"The aggregate demand deficiency preceded the financial crisis and was due to structural changes in income distribution. Since 1980, in most advanced countries the median wage has stagnated and inequalities have surged in favour of high incomes" (Fitoussi and Stiglitz, 2009, p.3). In other words, "although the crisis may have emerged in the financial sector, its roots are much deeper and lie in a structural change in income distribution that had been going

\footnotetext{
${ }^{2}$ This model has been extended by Kumhof et al. (2012) to include the foreign sector and analyze the interplay between rising inequality, financial instability and current account imbalances in an open economy.

${ }^{3}$ For a comprehensive survey of research on the links between income inequality and the Great Recession, see van Treeck and Sturn (2012).
} 
on for the past three decades" (Fitoussi and Saraceno, 2010, p.2). All in all, a real cause, for example, an increase of inequality, may result in a financial crisis. Accordingly, the expansion of finance (for instance through credit consumption) in a period of increasing inequality may only postpone the occurrence of the crisis. "While several authors have noticed that there might be a link between rising inequality and the crisis (e.g. Wade 2009, Rajan 2010, Stiglitz 2010), there is as of yet little systematic analysis" (Stockhammer, 2013).

"From a macroeconomic point of view, the increase in inequality triggers redistribution from households with high propensity to consume to households with a lower propensity to consume and/or from households credit constrained to households without such a constraint. The reasons for this difference in the propensities may be traced back to the work of Kalecki and Kaldor on income distribution (Kalecki, 1942; Kaldor, 1955), and it may be related to a minimum consumption (subsistence) level, to liquidity or credit constraints, or to satiation phenomena" (Fitoussi and Saraceno, 2010, p.7). "If propensities to consume differ, then the overall propensity to consume is affected by income distribution, and an increase in inequality causes it to decrease. The reduction of consumption demand, then, puts downward pressure on aggregate demand and on income (unless some compensation comes from other items, like government spending or external demand)" (Fitoussi and Saraceno, 2010, p.2).

Based on this literature, Russo et al. (2014) show that rising inequality results in more volatility that, in turn, makes more likely a large crisis. A similar result can be found in Dosi et al. (2013) in which innovation dynamics are investigated. As a matter of fact, rich people may accumulate higher wealth while poor people may suffer from low consumption, creating negative consequences at the macroeconomic level due to a lack of aggregate demand, increasing the likelihood of observing a crisis with large unemployment. Moreover, the "excessive" saving from the rich, through the financial intermediation of banks, may finance more consumption of the poor.

The aim of this paper is to contribute to this stream of literature by analyzing the interplay between increasing inequality and consumer credit in a complex macroeconomic system with financially fragile heterogeneous households, firms and banks. In order to analyze these complex issues, we extend previous works, such as Riccetti et al. (2014) and Russo et al. (2014), to investigate the impact of consumer credit on macroeconomic dynamics. In this paper we consider that households' consumption is characterized by "habit formation", and that households can have access to credit in order to finance the level of consumption exceeding own financial resources. Particularly, we focus on the role of inequality and financial instability in moving up the tendency of the system towards the crisis, due to the decline of the firms' profit rate (when no counter-tendencies are taken into account).

Indeed, a possible (but temporary) solution to the problem of aggregate demand deficiency is the availability of credit (coming from rich's saving) to finance the consumption of poor households. However, credit consumption can counteract the fall of the profit rate, at least for 
a certain period of time. ${ }^{4}$ However, in a context of low interest rates, the rise of indebtedness of poor agents may amplify the financial fragility of the economic system. For instance, an interest rate spike due to a change of the policy rate set by the central bank may lead to an increase of the delinquency rate. Such a problem has an impact on banks' capital: if one or more banks are not able to absorb the rise of non-performing loans, then some agent can fail with negative repercussions on the productive sector. Indeed, the decrease of banks' net worth may lead to credit rationing, so that firms cannot assume all the workers they need to produce the desired level of commodities. Moreover, rising unemployment results in a reduction of demand for goods, further deteriorating the financial conditions of firms. Some firms may go bankrupt, causing a further increase of non-performing loans and possibly leading to other bank defaults, according to a network-based financial accelerator mechanism (Delli Gatti et al. 2010; Riccetti et al., 2013). In the worst scenario, a financial collapse happens and an extended crisis may develop.

The paper is organized as follows. After this introduction, Section 2 presents the model setup: in particular, Subsection 2.1 reports the consumer credit mechanism; the evolution of agents' wealth is described in Subsection 2.2, while the behavior of policy makers is discussed in Subsection 2.3. Section 3 summarizes the model findings based on Monte Carlo simulations and sensitivity analyses. Section 4 concludes.

\section{The model}

In what follows, we explain the main features of the model, from agents' behavior to the working of markets and the structure of the matching mechanism governing the decentralized interaction among a multitude of heterogeneous agents.

Our economy evolves over a time span $t=1,2, \ldots, T$ and it is composed of households $(h=$ $1,2, \ldots, H)$, firms $(f=1,2, \ldots, F)$, banks $(b=1,2, \ldots, B)$, a central bank, and the government. Agents are boundedly rational and live in an incomplete and asymmetric information context, thus they follow simple rules of behavior and use adaptive expectations.

Agents interact in four markets: credit, labor, goods and deposit. Here, we describe the structure and the working of markets.

- Credit market: firms and households (demand) and banks (supply) interact in the credit market. Firm's $f$ credit demand $B_{f t}^{d}$ at time $t$ depends on its net worth $A_{f t}$ and the leverage target $l_{f t}$ :

$$
B_{f t}^{d}=A_{f t} \cdot l_{f t}
$$

\footnotetext{
${ }^{4}$ According to a Marxian perspective, consumer credit and, in general, the expansion of finance can be considered as factors that may counteract, at least for a while, the tendency of the profit rate to fall, when the economy has reached the limit of its "material expansion" (Russo, 2014).
} 
The evolution of the leverage target changes according to expected profits (and inventories): if expected profits are above the expected interest rate (and there are few inventories), the firm raises its target leverage, and vice versa, as follows:

$$
l_{f t}= \begin{cases}l_{f t-1} \cdot(1+\alpha \cdot U(0,1)), & \text { if } \pi_{f t-1} /\left(A_{f t-1}+B_{f t-1}\right)>i_{f t-1} \text { and } \hat{y}_{f t-1}<\psi \cdot y_{f t-1} \\ l_{f t-1}, & \text { if } \pi_{f t-1} /\left(A_{f t-1}+B_{f t-1}\right)=i_{f t-1} \text { and } \hat{y}_{f t-1}<\psi \cdot y_{f t-1} \\ l_{f t-1} \cdot(1-\alpha \cdot U(0,1)), & \text { if } \pi_{f t-1} /\left(A_{f t-1}+B_{f t-1}\right)<i_{f t-1} \text { or } \hat{y}_{f t-1} \geq \psi \cdot y_{f t-1}\end{cases}
$$

where $\alpha>0$ is the maximum percentage change of the target leverage, $U(0,1)$ is a uniformly distributed random number, $\pi_{f t-1}$ is the previous period gross profit, $B_{f t-1}$ is the debt of the past period, $i_{f t-1}$ is the nominal interest rate paid on debts, $\hat{y}_{f t-1}$ are inventories, $0 \leq \psi \leq 1$ is a threshold for inventories compared to past production $y_{f t-1}$. (For household credit demand, see Subsection 2.1.)

Banks set their credit supply $B_{b t}^{s}$ depending on their net worth $A_{b t}$, deposits $D_{b t}$, and the quantity of money provided by the central bank $m_{b t}$ :

$$
B_{b t}^{d}=\nu_{b t} \cdot \min \left(\hat{k}_{b t}, \bar{k}_{b t}\right)
$$

where $\hat{k}=\gamma_{1} \cdot A_{b t}, \bar{k}=\gamma_{2} \cdot A_{b t}+D_{b t-1}+m_{b t}$, and $\nu_{b t}$ is a bank-specific variable for deciding the allocation of money between private lending and government bonds. This variable can assume values from 0 (no private lending) to 1 (no government bonds) and it is set as follows: $\nu_{b t}=\nu_{b t-1} \cdot(1 \pm \alpha \cdot U(0,1))$, where a random amount is added to or subtracted from the previous value of the variable if the ratio between the expected flow of interests paid by firms and households and the total credit extended is higher/equal or lower than the remuneration on government bonds, respectively.

Moreover, we assume that, if the sum of desired government bonds exceeds the amount of outstanding public debt, then the effective investment is proportionally rescaled (based on the relative demand from different banks); instead, if public debt exceeds the banks' desired amount, then the central bank buys the difference. In this way, the central bank (in accordance with the government) can keep the interest rate on bonds as low as desired. This clearly leads to a (partial) monetization of the public debt. All results we will discuss below depend on this assumption of a close collaboration between the government and the central bank in managing public debt dynamics. ${ }^{5}$ In order to

\footnotetext{
${ }^{5} \mathrm{~A}$ possible extension of the analysis would include the testing of different allocation rules between sovereign bonds and private lending and the investigation of a different relationship between the government and the central bank: for instance, we could assume that the central bank is not allowed to buy government bonds on the primary market. This should be particularly relevant for analyzing the current evolution of economic and financial conditions in the Eurozone.
} 
keep the model as simple as possible, we do not allow households to buy government securities: they can only decide either to deposit money in a bank or keep money as cash. As a consequence, the central bank plays a major role in buying government securities, especially when when private banks reduce their demand. ${ }^{6}$

Banks have to comply with regulatory constraints, that is $\gamma_{1}>0$ and $0 \leq \gamma_{2} \leq 1$ that represent, respectively, the maximum admissible leverage and maximum percentage of capital to be invested in lending activities), and a credit concentration limit (that is, banks can lend to a single firm up to a maximum fraction $\beta$ of the total amount of the credit $\left.B_{b t}^{d}\right)$.

Finally, the bank $b$ charges an interest rate on loans to the firm $f$ or household $h$ according to the following equation:

$$
i_{b f t}=i_{t}^{C B}+\hat{i}_{b t}+\bar{i}_{x t}
$$

where $i_{t}^{C B}$ is the nominal interest rate set by the central bank, $\hat{i}_{b t}$ is a bank-specific component, and $\bar{i}_{x t}=\rho^{l_{x t}} / 100$ is a firm-specific (in this case $x=f$ ) or a household specific component $(x=h)$, that is, a risk premium on the firm $f$ or household $h$ target leverage $l_{x t}{ }^{7}$ and $\rho$ is a positive parameter. The bank-specific component decreases if the bank does not manage to lend all the credit supply to firms and vice versa.

- Labor market: firms and government (demand side) and households (supply side) interact in the labor market. On the demand side, the government hires a fraction $g$ of households picked at random from the whole population. The remaining part is available for working in private firms. The wage bill paid by firm $f$ is financed by net worth and bank credit: $A_{f t}+B_{f t}$. Thus, labor demand relies on retained profits and the target leverage (see Equation 2). This means that labor demand depends on expected profits, which include the expected demand for goods and production costs (based on adaptive expectations). Then, the firm compares the expected profit with financial costs (the interest rate on bank loans): if the former is higher than the latter, then the firm increases the labor demand, and vice versa.

On the supply side, each worker posts a wage $w_{h t}$ that increases if he was employed in the previous period, and vice versa. Moreover, the required wage has a minimum related to the price of a good. As a result of the decentralized matching between labor supply and demand, each firm ends up with a number of workers $n_{f t}$ and a residual cash (insufficient to hire an additional worker) and a fraction of households may remain unemployed. The wage of unemployed people is set equal to zero.

\footnotetext{
${ }^{6}$ This is another assumption we could remove in a future work in which the whole mechanism of portfolio allocation for private agents (that is, households, firms and banks) and the operation of policy makers are better implemented.

${ }^{7}$ The target leverage is the ratio between required credit and firm's net worth $(x=f)$ or household's wealth $(x=h)$
} 
- Goods market: households (demand side) and firms (supply side) interact in the goods market. On the demand side, households set the desired consumption on the basis of their disposable income, wealth and bank credit. (See Subsection 2.1 for details on the consumption function.)

Firms produce consumption goods on the basis of hired workers as follows:

$$
y_{f t}=\phi \cdot n_{f t}
$$

where $\phi \geq 1$ is a productivity parameter. They put their current period production and previous period inventories $\hat{y}_{f t-1}$ in the goods market. The selling price increases if in the previous period the firm managed to sell all the output, while it reduces if it has positive inventories:

$$
p_{f t}= \begin{cases}p_{f t-1} \cdot(1+\alpha \cdot U(0,1)), & \text { if } \hat{y}_{f t-1}=0 \\ p_{f t-1} \cdot(1-\alpha \cdot U(0,1)), & \text { if } \hat{y}_{f t-1}>0\end{cases}
$$

Moreover, the minimum price at which the firm wants to sell its output is set such that it is at least equal to the average cost of production. As a consequence of the interaction between supply and demand sides in the goods market, each household ends up with a residual cash that is not enough to buy additional goods and that he will try to deposit in a bank. At the same time, firms may remain with unsold goods (inventories) that they will try to sell in the next period.

- Deposit market: banks (demand) and households (supply) interact in the deposit market. Banks offer an interest rate on deposits according to their funds' requirement:

$$
i_{b t}^{D}= \begin{cases}i_{b t-1}^{D} \cdot(1-\alpha \cdot U(0,1)), & \text { if } \bar{k}_{b t}-B_{b t}-\Gamma_{b t}>0 \\ \min \left\{i_{b t-1}^{D} \cdot(1+\alpha \cdot U(0,1)), i_{C B t}\right\}, & \text { if } \bar{k}_{b t}-B_{b t}-\Gamma_{b t}=0\end{cases}
$$

where $\Gamma_{b t}$ is the amount of public debt bought by bank $b$ at time $t$. If a bank exhausts the credit supply (by lending to private firms, households or government), then it decides to increase the interest rate paid on deposits to attract new depositors, and vice versa. However, the interest rate on deposits can increase until a maximum given by the policy rate $i_{t}^{C B}$, which is the rate at which banks could refinance from the central bank. Households set the minimum interest rate they want to obtain on bank deposits as follows:

$$
i_{i t}^{D}= \begin{cases}i_{i t-1}^{D} \cdot(1-\alpha \cdot U(0,1)), & \text { if } D_{i t-1}=0 \\ i_{i t-1}^{D} \cdot(1+\alpha \cdot U(0,1)), & \text { if } D_{i t-1}>0\end{cases}
$$

where $D_{i t-1}$ is the individual $i$ 's deposit in the previous period. Accordingly, households that in the previous period found a bank paying an interest rate higher or equal to the desired one decide to ask for a higher remuneration. In the opposite case, if they do not 
find a bank satisfying their requirements, they reduce the minimum rate at which they would deposit money. We assume that each household deposits all the available money in a single bank that offers the required interest rate.

Finally, the interaction mechanism that matches the demand and the supply sides of the four markets follows a common decentralized matching protocol. In particular, interaction develops in the following way: a random list of agents on the demand side is set, then the first agent on the list observes a random subset of potential counterparts on the supply side, the size of which depends on a parameter $0<\chi \leq 1$ (that proxies the degree of imperfect information), and chooses the cheapest one. After that, the second agent on the list performs the same activity on a new random subset of the updated potential partner list. The process iterates until the end of the demand side list. Subsequently, a new random list of agents in the demand side is set and the whole matching mechanism continues until either one side of the market (demand or supply) is empty or no further matchings are feasible because the highest bid (for example, the money available to the richest firm) is lower than the lowest ask (for example, the lowest wage asked by unemployed workers).

\subsection{Households: consumption demand, credit demand and wealth evolution}

Households set their desired consumption on the basis of their disposable income, wealth, and past consumption. In particular, they compare the level of consumption deriving from their propensity to consume income and wealth, that is $c_{h t}^{*}=c_{1} \cdot w_{h t-1}+c_{2} \cdot A_{h t-1}$, where $0<c_{1} \leq 1$ is the propensity to consume income, $0 \leq c_{2} \leq 1$ is the propensity to consume the wealth $A_{h t-1}$, with how much they consumed before, $c_{h t-1}$. Then, they choose the larger one: $c_{h t}^{d}=\max \left\{c_{h t}^{*}, c_{h t-1}\right\}$. Accordingly, households are characterized by habit formation in consumption behavior. Moreover, we assume that, if the amount $c_{h t}^{d}$ is smaller than the maximum price of one good $\bar{p}$, then $c_{h t}^{d}=\bar{p}$; that is the household would like to buy at least one good (independently of previous behavioral rules).

By introducing consumer credit, we allow households to borrow the money needed to finance consumption exceeding their financial resources. Therefore, if the household does not have enough money to buy the amount $c_{h t}^{d}$, he can ask for credit from one or more banks (according to the usual matching mechanisms). The amount of required credit is equal to the difference between $c_{h t}^{d}$ and available funds (income plus wealth). However, households also look at the financial costs of consumer credit; they demand less credit if the interest rate to be paid on consumer credit is high, and vice versa, according to the following equation:

$$
c c_{h t}^{d}=\max \left\{0, \mu \cdot c_{h t}^{d} \cdot\left(1-r_{t-1}^{c c}\right)-\left(w_{h t-1}+A_{h t-1}\right)\right\}
$$

where $r_{t-1}^{c c}$ is the (past period) mean interest rate on consumer credit, and $0 \leq \mu \leq 1$ is a 
parameter. $^{8}$ The presence of the term $\left(1-r_{t-1}^{c c}\right)$ in Equation 9 is a simple way to introduce a negative relation between the demand for consumer credit and its price, i.e. the interest rate.

After the interaction in the credit market, households go to the goods market with an amount $\bar{c}_{h t}^{d}$ to be spent equal to $c_{h t}^{d}$ if they do not need consumer credit or if banks lend all the required credit, while it is a lower amount equal to the sum of disposable income, wealth and (possibly) bank credit if they ask for consumer credit and do not (fully) obtain it.

After purchasing goods, households try to deposit their savings. Savings are composed of the employed workers income (net of taxes) plus consumer credit (if asked and received), plus the previous period wealth, plus the interest received on the previous period deposits (if present), plus previous period dividends from firms and banks, ${ }^{9}$ less the cost of effective consumption, less the interest paid on previous period consumer credit (if present), less tax on wealth. ${ }^{10}$

Finally, households linked to defaulted banks lose a fraction of their deposits (see next Subsection for details). In the same way, if a household goes bankrupt, the banks that lent money lose a fraction of provided credit. In general, a "loss given default rate" (LGDR) can be computed for each agent (household, firm or bank) going bankrupt, which is equal to $-A / B$, where $A$ is the agent's net worth that is negative in the case of default, and $\mathrm{B}$ is the debt. For example, consider a bankrupted agent with net worth $A=-10$ and debt $B=100$ : the agent has a cash amount of 90 that can be employed partially to fulfill the debt. The LGDR is then equal to $10 \%$ or, equally, the "recovery rate" (RR) is $(-A+B) / B$, in this case $90 \%$.

\subsection{Profits, dividends and wealth dynamics of firms and banks}

At the end of the interactions in the four markets, every firm $f$ and bank $b$ calculates its profit.

Firm profits are equal to revenues, $p_{f t} \cdot \bar{y}_{f t}$, where $p_{f t}$ is the price set by the firm $f$ on its goods, and $\bar{y}_{f t}$ is the number of sold goods), less the sum of wages paid to employed workers and the sum of interests paid on bank loans. Firms pay taxes and distribute a percentage $\delta_{f t}$ of positive profits as dividends to households. The fraction $0 \leq \delta_{f t} \leq 1$ goes down if in the previous period the firm produced and sold all the goods (no inventories, then it wants to retain a larger share of profits to enlarge production), and vice versa. ${ }^{11}$

\footnotetext{
${ }^{8}$ Remember that the interest rate set by the bank $b$ on the credit extended to household $h$ at time $t$ is computed according to Equation 4 based on the same procedure for both firms and households.

${ }^{9}$ Net of the amount needed for new entrant firms and banks replacing defaulted ones, see next Subsection; the fraction of dividends obtained by household $h$ is proportional to the household $h$ 's wealth compared with overall households' wealth.

${ }^{10}$ Only applied on wealth exceeding a threshold that is a multiple of the average goods price.

${ }^{11}$ The assumption that dividends only depend on investment needs may seem restrictive, for instance because firms do not change the payout policy during a crisis. However, there is ample literature supporting the fact
} 
Bank profits are equal to interest gained on lending to non-defaulted firms and households, plus interest obtained on government securities, less the interests paid to depositors and Central Bank, and less the bad debt due to bankrupted agents. As for firms, banks pay taxes and distribute dividends on positive profits. The dividend fraction $0 \leq \delta_{b t} \leq 1$ evolves according to the following rule: if the bank does not manage to lend the desired supply of credit then it decides to distribute more dividends (because it does not need high reinvested profits), and vice versa.

The profit is added (or subtracted, in the case of a loss) to the previous period firm's wealth $A_{f t-1}$ or bank's wealth $A_{b t-1}$ and the new amount of wealth is computed.

If $A_{f t} \leq 0$, then the firm goes bankrupt and a new entrant replaces the bankrupted agent according to a one-to-one replacement. Banks linked to defaulted firms lose a fraction of their loans, but recover the remaining part with a recovery rate equal to $\left(A_{f t}+B_{f t}\right) / B_{f t}$.

If $A_{b t} \leq 0$, then the bank is in default and a new entrant takes its place. Households linked to defaulted banks lose a fraction of their deposits (the loss given default rate is calculated as $\left.1-\left(A_{b t}+D_{b t}\right) / D_{b t}\right)$.

The new entrant (firm or bank) starts with an initial net worth equal to a multiple of the average goods price and the money needed to finance entrants is subtracted from households' wealth (proportionally to their resources). ${ }^{12}$

\subsection{Government and central bank}

Government's current expenditure is given by the sum of wages paid to public workers and the interests paid on public debt. Moreover, government collects taxes on incomes and wealth and receives interest gained by the central bank. The difference between expenditures and revenues gives rise to the public deficit $\Psi_{t}$. Consequently, public debt is $\Gamma_{t}=\Gamma_{t-1}+\Psi_{t}{ }^{13}$ The presence of the government as an acyclical sector is a very important feature of the model.

that the payout policy has been increasingly oriented to the maximization of the shareholder value and not so much to liquidity or solvency problems that can emerge during a crisis. This holds both for firms and banks. For instance, Lazonick and O'Sullivan (2000) show that non-financial corporations has been characterized by a shift from a retain and reinvest strategy to a downsize and distribute strategy. Moreover, over the decade 2001-2010, the corporations in the S\&P 500 Index distributed the $40 \%$ of their profits on cash dividends, but also another $54 \%$ on stock buybacks (Lazonick, 2013). Finally, the literature highlights that even when the financial crisis started and the banking system suffered the depletion of common equity through losses, banks continued to pay dividends, in spite of widely anticipated credit losses, because high dividend payments signal to the market the soundness of the bank (see, for instance, Acharya et al., 2011 and Brogi, 2010).

${ }^{12}$ In case private wealth is not enough, then government intervenes. (However, this never happens in the simulations we present in the paper.)

${ }^{13}$ The evolution of public deficit (and debt) depends on the parameter setting. We choose parameter values such that the public deficit to gdp ratio oscillates around $3 \%$ (in normal times). As a consequence, the public debt to gdp ratio, which initially increases, tends to stabilize after a while, such as when the growth of nominal gdp due to inflation is above the growth rate of public debt. 
Table 1: Parameter setting, baseline model.

\begin{tabular}{c|c|c}
\hline $\mathrm{H}$ & number of individuals & 500 \\
$\mathrm{~F}$ & number of firms & 80 \\
$\mathrm{~B}$ & number of banks & 10 \\
$\alpha$ & adjustment parameter & 0.05 \\
$\chi$ & matching imperfect information & 0.2 \\
$\psi$ & inventory threshold & 0.1 \\
$\gamma_{1}$ & max bank's leverage & 10 \\
$\gamma_{2}$ & max $\%$ of bank's invested capital in lending & 0.5 \\
$\beta$ & max bank's lending to single firm & 0.1 \\
$\rho$ & risk premium on loans & 2 \\
$c_{1}$ & propensity to consume current income & 0.8 \\
$c_{2}$ & propensity to consume wealth & 0.3 \\
$\phi$ & firm's productivity & 3 \\
$\tau$ & tax rate on income & 0.3 \\
$g$ & \% of public workers on population & 0.3 \\
$\mu$ & consumer credit parameter & 0 \\
\hline \hline
\end{tabular}

Indeed, hiring public workers, the government provides a fraction of the aggregate demand. In this way, it partially stabilizes the economy by reducing output volatility.

The central bank decides the policy rate $i_{C B t}$ and the quantity of money to put into the system in accordance with the interest rate. In order to do that, the central bank observes the aggregate excess supply or demand in the credit market and sets an amount of money $M_{t}$ to reduce the gap in the subsequent period of time. Model dynamics are influenced by the assumptions we made about the operation of the government and the central bank. The fundamental hypothesis is that the two policy makers collaborate strictly in managing the public debt; indeed, the central bank is committed to buy outstanding government securities.

\section{Model results}

The dynamics of the model are studied by means of computer simulation. In what follows, we present and discuss simulation results. Consider that the model focuses on business cycle fluctuations. We perform a short/medium run analysis; we do not consider factors underlying long run growth (for instance, labor and capital productivity).

As for the basic mechanisms of our artificial macroeconomy (see also Riccetti et al., 2014), we observe the emergence of endogenous business cycles with the following pattern: an increase in firms' profit determines an expansion of production resulting in more employment and, if banks extend the required credit, this effect could be further amplified; the fall of the 
unemployment rate increases wage inflation that, on the one hand, expands the aggregate demand, while, on the other hand, reducing firms' profit, possibly causing an inversion of the business cycle. Then, there is a dynamic relationship between unemployment and the profit rate, enlarged by a financial accelerator mechanism. Business fluctuations are mitigated by the government (an acyclical sector) that plays a central role in reducing the output volatility through stabilizing aggregate demand. The system can remain trapped in large and extended crises: wage reduction due to growing unemployment does not reverse the cycle, but generates a lack of aggregate demand that amplifies the recession in a vicious circle for which the fall of purchasing power prevents firms from selling commodities. Firms decrease production, unemployment continues to rise, and the recession further deteriorates.

In this paper we want to understand how the presence of consumer credit influences the dynamics of the model. We focus on the unemployment rate, given that it is perfectly related to real GDP (i.e., we assumed that firms have fixed productivity). First of all, we run simulations for a time span of $T=500$ periods, based on the parameter setting reported in Table 1. In particular, we focus on a comparison between two "extreme" cases: (i) a baseline scenario with no consumer credit $(\mu=0)$, and (ii) a computational treatment that considers the presence of consumer credit $(\mu=1)$. In the second part of this section, we provide some sensitivity analyses to study the impact of different levels of consumer credit (with values of $\mu$ from 0 to 1 with step 0.1 ) on macroeconomic dynamics. Some policy implications emerge.

\subsection{Monte Carlo analysis: Baseline scenario vs. consumer credit}

We perform two Monte Carlo (hereafter MC) analyses (with the same initial random seeds), running 500 simulations in each. In the first analysis, we use a model without consumer credit (hereafter $\mathrm{CC}$ ): desired consumption cannot exceed the sum of household disposable income and wealth. In the second one, we allow household borrowing to finance consumption.

Figure 1 shows the time evolution of the unemployment rate in the two computational treatments: (i) the baseline model (without CC) and (ii) the model with CC. In particular, we perform $1000 \mathrm{MC}$ simulations, 500 runs without $\mathrm{CC}$ and 500 with $\mathrm{CC}$, and then we compute the unemployment rate for each time $t$ as the average of the unemployment rates across the MC simulations for each of the two scenarios. We also compute the mean absolute deviation for each $t$ and then use it to add error bars around the mean unemployment rate.

For a certain period of time, the unemployment rate is smaller when households can finance (a fraction of) consumption through credit that sustains the aggregate demand. For instance, the unemployment rate for the model with CC (solid line in Figure 1) is below the level of the baseline scenario (dashed line in Figure 1), almost half of the whole simulation period. Indeed, a reduction of aggregate demand, for instance, due to a rise of unemployment, has different effects on an economy with or without CC. When households have access to credit to finance consumption, a decrease of aggregate demand can be counteracted by more household 
Figure 1: Monte Carlo analysis, 500 simulations without CC (solid line) and 500 simulations with CC (dashed line). For each time period $t$, we calculated the average value of the unemployment rate (and the corresponding mean absolute deviations to add the \pm mad interval) across 500 Monte Carlo replications for each of the two scenarios.

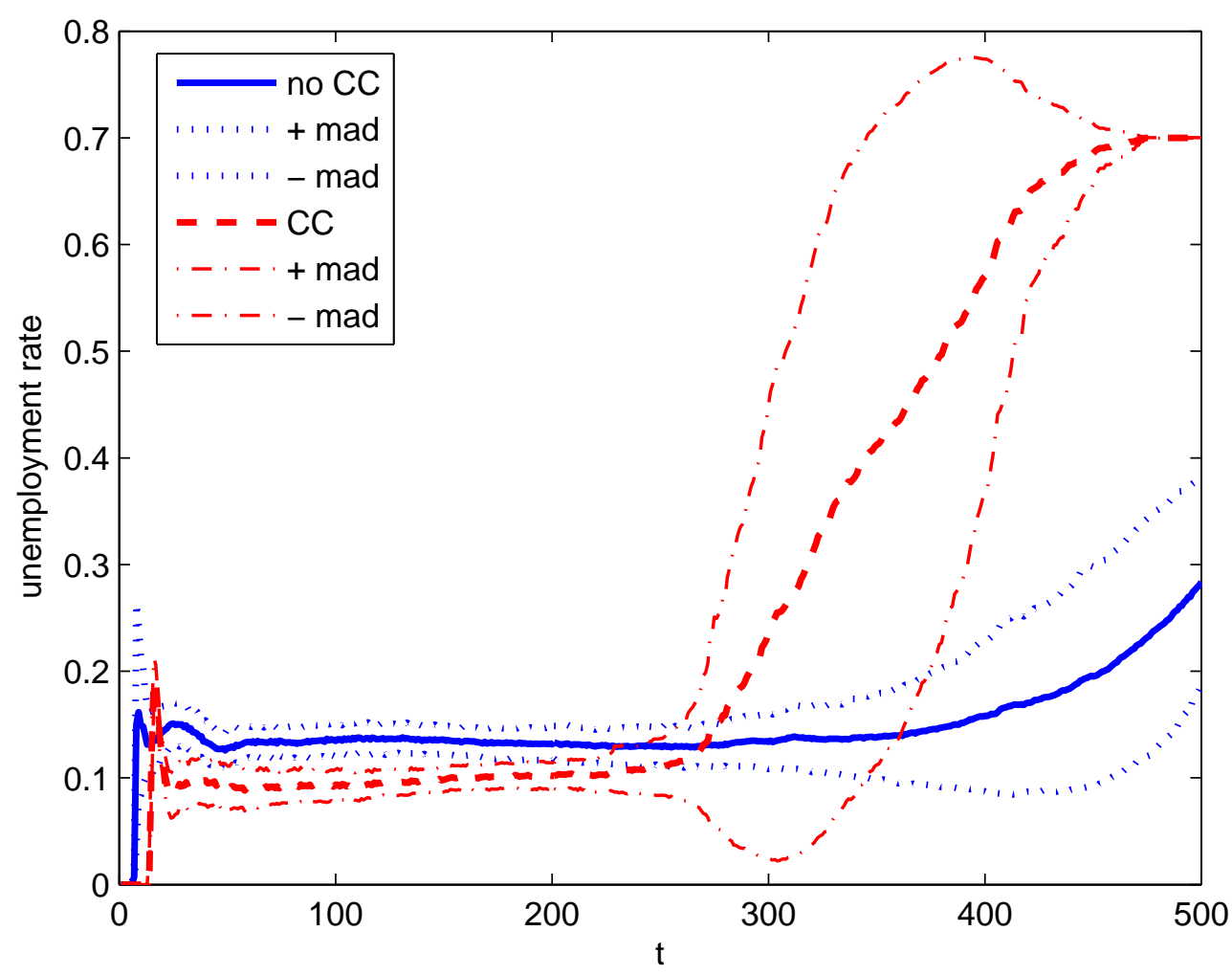


Figure 2: Monte Carlo analysis, 500 simulations with CC. For each time period $t$, we calculated the average value of the cross-correlation between consumer credit and unemployment.

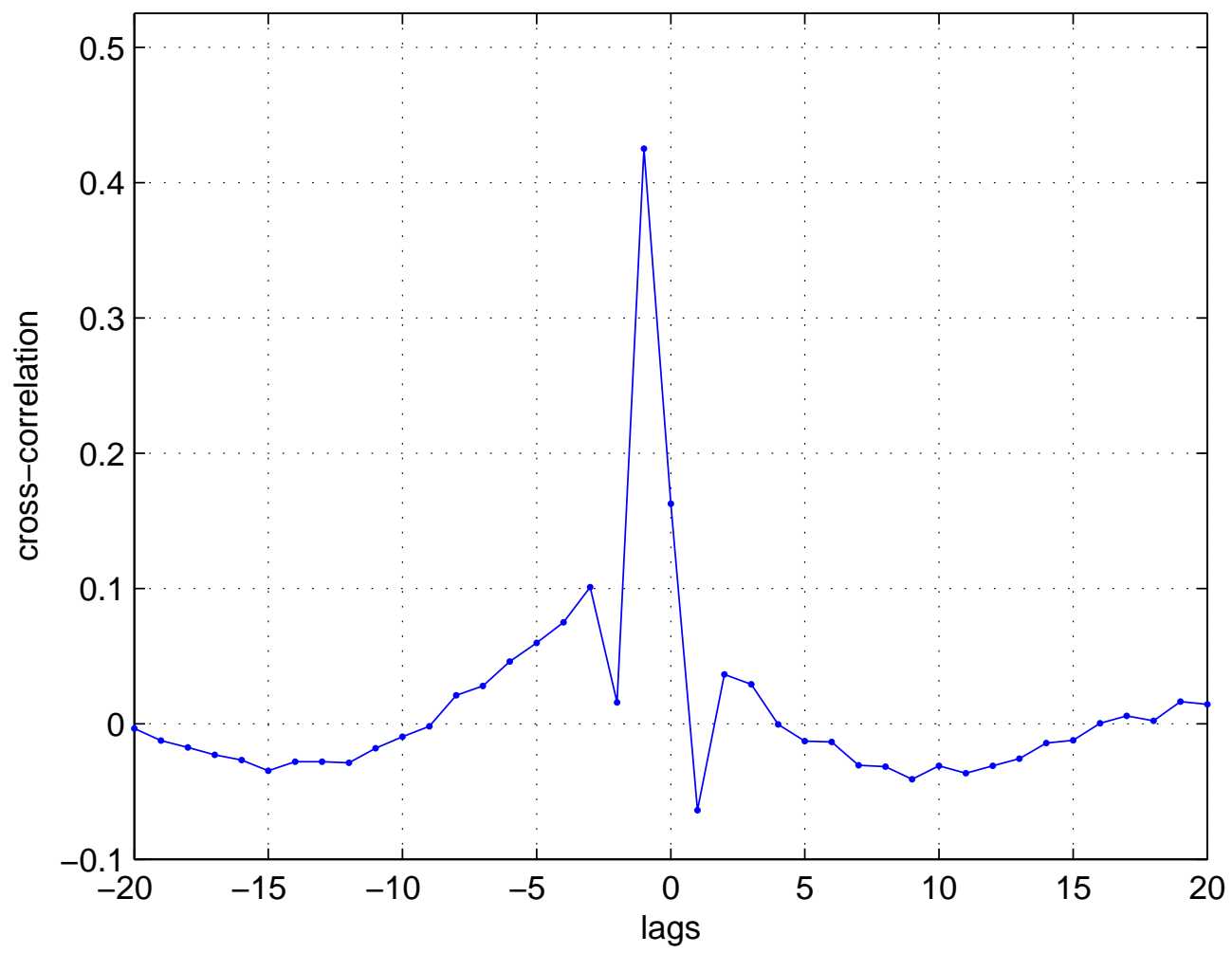

debt. In particular, the rate of unemployment is positively correlated with consumer credit, as shown in Figure 2, at lag0 and lag $-1 .{ }^{14}$ This suggests that more unemployment results in an extended access to consumer credit. There is also a slight negative correlation at lag +1 , suggesting that an increase of consumer credit makes unemployment decline. The main feature is, however, that for a quite long time the economy with $\mathrm{CC}$ performs better than the system with no CC. Nevertheless, for successive periods, the unemployment rate tends to rise and the economy evolves towards a large crisis. A similar tendency characterizes the evolution of the unemployment rate for the model without CC, although the economy takes a longer time to evolve towards a large crisis. ${ }^{15}$

The underlying mechanisms are the same in the two cases (as well as in the basic case

\footnotetext{
${ }^{14}$ Cross-correlations are computed by averaging values across MC simulations for the period from $t=101$ to $t=200$, before the large crisis.

${ }^{15}$ In particular, all the simulations with CC converge to a complete crash of the private economy: when approaching the end of the simulation period, the level of unemployment is always $70 \%$ in the CC scenario because no more firms demand labor and only a fraction $g=0.3$ of households are employed by the public sector; consequently, there is no more dispersion around the mean value of unemployment and the mean absolute deviation is zero.
} 
analyzed in Riccetti et al., 2014) as shown, for instance, by the emergence of the Phillips curve, meaning an inverse relation between the unemployment rate and wage inflation (see Figure 3): ${ }^{16}$ the only significant difference introduced by consumer credit is that the average unemployment rate is lower and the average wage inflation higher, compared to the "no CC" scenario.

The presence of consumer credit leads to a lower average value of the public deficit to gdp ratio (almost 3\%) compared to the no CC case (slightly above 4\%). Obviously, this causes a public debt to gdp ratio which is lower with CC (around 133\%) than without it (200\%). In both cases, however, the central bank plays a fundamental role in managing macroeconomic conditions through debt monetization. Consider, indeed, that the fraction of public debt held by private banks is around $20 \%$ in both the baseline and the CC scenario. The remaining part is bought by the central bank. This is also due to the simplifing assumption that households are not allowed to buy government securities.

However, after a beneficial effect on the macroeconomy, the presence of consumer credit introduces more instability, as we can see observing both the enlargement of error bars in Figure 1 and the increase of macroeconomic volatility (as measured by the average value of the mean absolute deviation of unemployment rates across MC simulations) displayed in the upper-left panel of Figure 4. However, household debt causes instability only after a certain period during which the economic system is as stable as (or even more stable than) in the "no CC" case.

A fundamental difference between the two scenarios regards the degree of inequality. The introduction of consumer credit allows households to buy more goods, based on the consumption function with habit formation, overcoming the budget constraint due to own financial resources. This boosts the aggregate demand, resulting in a lower unemployment rate. As time elapses, however, the payment of interests on household debt reduces their wealth that causes a reduction of consumption (remember that desired consumption depends positively on both income and wealth). As a consequence, households may ask for more consumer credit and, if banks allow households to borrow more, consumption may remain stable or even increase, despite the reduction of household wealth. But this leads to a further reduction of wealth for indebted households that eventually results in higher inequality. All in all, simulations with CC exhibit more inequality (as measured by the Gini index computed on households' wealth) compared with the "no CC" scenario (see upper-right panel in Figure 4).

The rise of inequality, along with an expansion of credit implying a larger financial leverage of the banking sector (see bottom-left panel in Figure 4), creates the basis for a large crisis that happens before and with a stronger magnitude than in the "no CC" scenario. All in all, the presence of consumer credit accelerates the tendency of the economic system to-

\footnotetext{
${ }^{16}$ In this figure, we consider only the period of time from $t=101$ to $t=200$, the stable phase before the crisis.
} 
Figure 3: Monte Carlo analysis, 500 simulations without CC (circles) and 500 simulations with CC (stars). For each time period $t$ in the time interval 101-200 we calculated the average value of the unemployment rate and of wage inflation, across 500 Monte Carlo replications for each of the two scenarios.

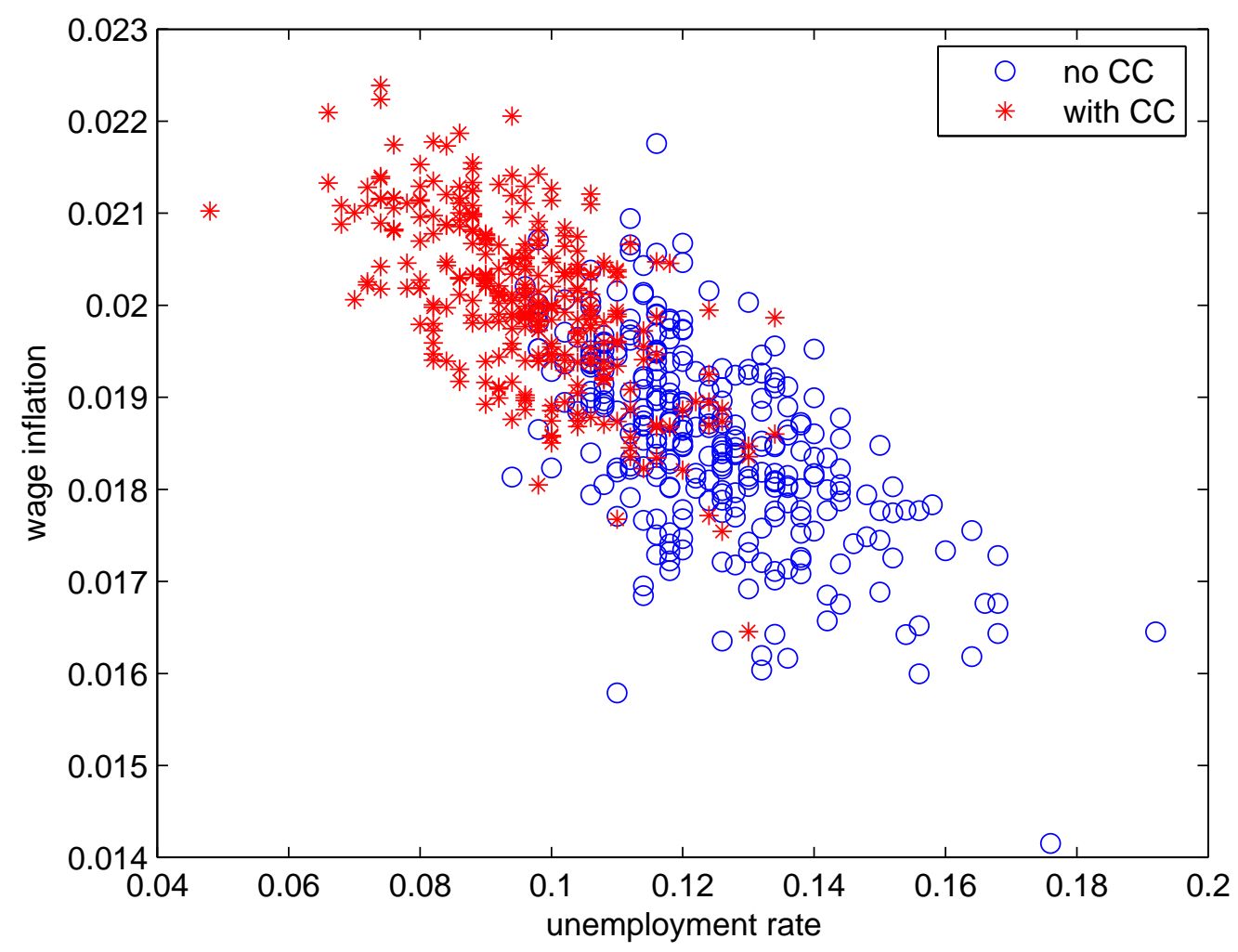


Figure 4: Monte Carlo analysis, 500 simulations without CC (solid line) and 500 simulations with CC (dashed line). For each time period $t$, we calculated the average value of the (i) unemployment volatility, (ii) Gini index on households' wealth, (iii) banks' exposure (the ratio between effective credit to firms and households and own capital), and (iv) firms' profit rate (the ratio between net profits and own capital), across 500 Monte Carlo replications for each of the two scenarios.
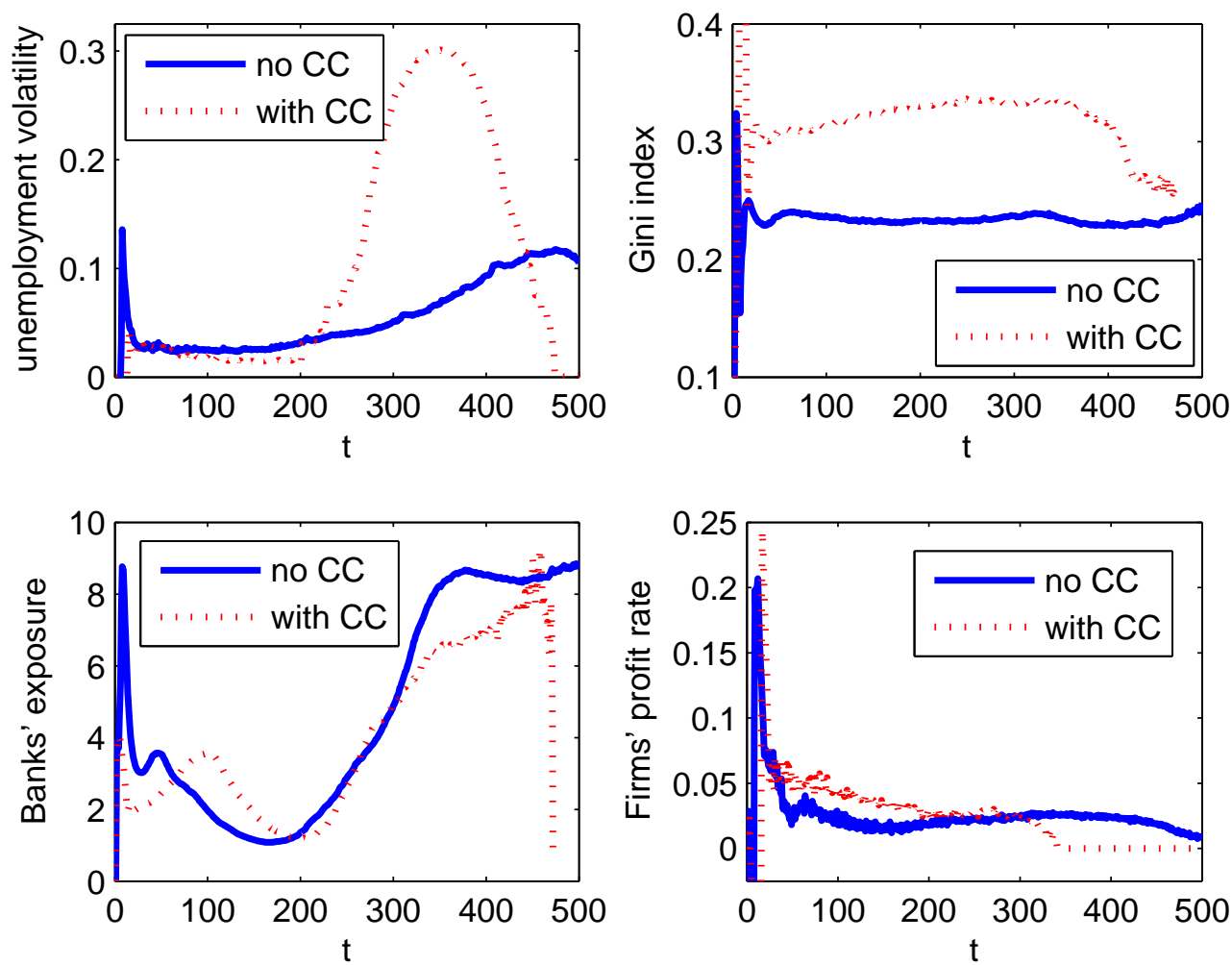
wards the crisis. ${ }^{17}$ Therefore, there are pros and cons of introducing consumer credit in the macroeconomy.

The tendency towards the crisis is related to the dynamics of the productive sector's profit rate. The bottom-right panel in Figure 4 displays the time evolution of the mean values (for each time $t$ across $500 \mathrm{MC}$ simulations for each treatment) of firms' profit rate in the two scenarios. As a consequence, the profit rate of the banking system declines, even though its level is higher in the CC case than in the "no CC" scenario due to the interest paid by households on their debt. This pattern characterizes the stable phase of the model, during which the average unemployment rate with CC is lower than in the basic case. The same holds for firms that face a higher level of aggregate demand because of the presence of consumer credit. As the profit rate approaches zero, firms tend to decrease the demand of credit to finance production (they prefer to distribute dividends to stakeholders). There is then a process of deleveraging along with the tendency of the economy towards the crisis.

\subsection{Sensitivity analysis for different levels and timings of consumer credit}

In this subsection, we perform a sensitivity analysis on the parameter $\mu$ (see Equation 9). In other words, we want to explore the effects of introducing higher levels of consumer credit. Accordingly, we consider various scenarios with different values of the parameter $\mu$ : from 0 to 1 with a step 0.1 . Figure 5 reports the time evolution of the average unemployment rate (calculated across 100 Monte Carlo simulations for each value of the parameter): higher levels of $\mu$ result in more unemployment, even though there is a non-linear relation. It seems as though intermediate levels perform worse than low or high levels of consumer credit; in fact, the high value of mean unemployment is mainly due to the final period of large crises.

When we investigate macroeconomic dynamics during a stable phase, for instance, from $t=101$ to $t=200$, things change. As shown in Figure 6 , the average unemployment rate (calculated across $100 \mathrm{MC}$ simulations for each value of $\mu$ from 0 to 1 with step 0.1 ) when households have access to consumer credit is always smaller than in the case with "no CC" (when $\mu=$ $0)$. This confirms that $\mathrm{CC}$ has a positive effect on the macroeconomic system for a quite long period of time, before accelerating the tendency of the system towards the crisis. Perhaps it is the presence of $\mathrm{CC}$ more than its level that has a major impact on macroeconomic evolution (almost independently of the value of $\mu$ ).

Moreover, the presence of $\mathrm{CC}$ and its level as modulated by the parameter $\mu$ has different effects on aggregate demand and on the tendency towards the crisis depending on when it

\footnotetext{
${ }^{17}$ Consider that the model takes a quite long time before that a large crisis emerges. Moreover, we do not introduce any counter-tendency, such as a public intervention based on a large investment plan, an institutional change, technological innovation, and so on. In those cases the economy should recover and work for many other periods. This is what we will investigate in a future version of the model incorporating long-run factors.
} 
Figure 5: Sensitivity analysis, 100 simulations for each value of the parameter $\mu$ from 0 to 1 by step 0.1 . For each value of $\mu$, we calculated the average value of the unemployment rate across the whole simulation period.

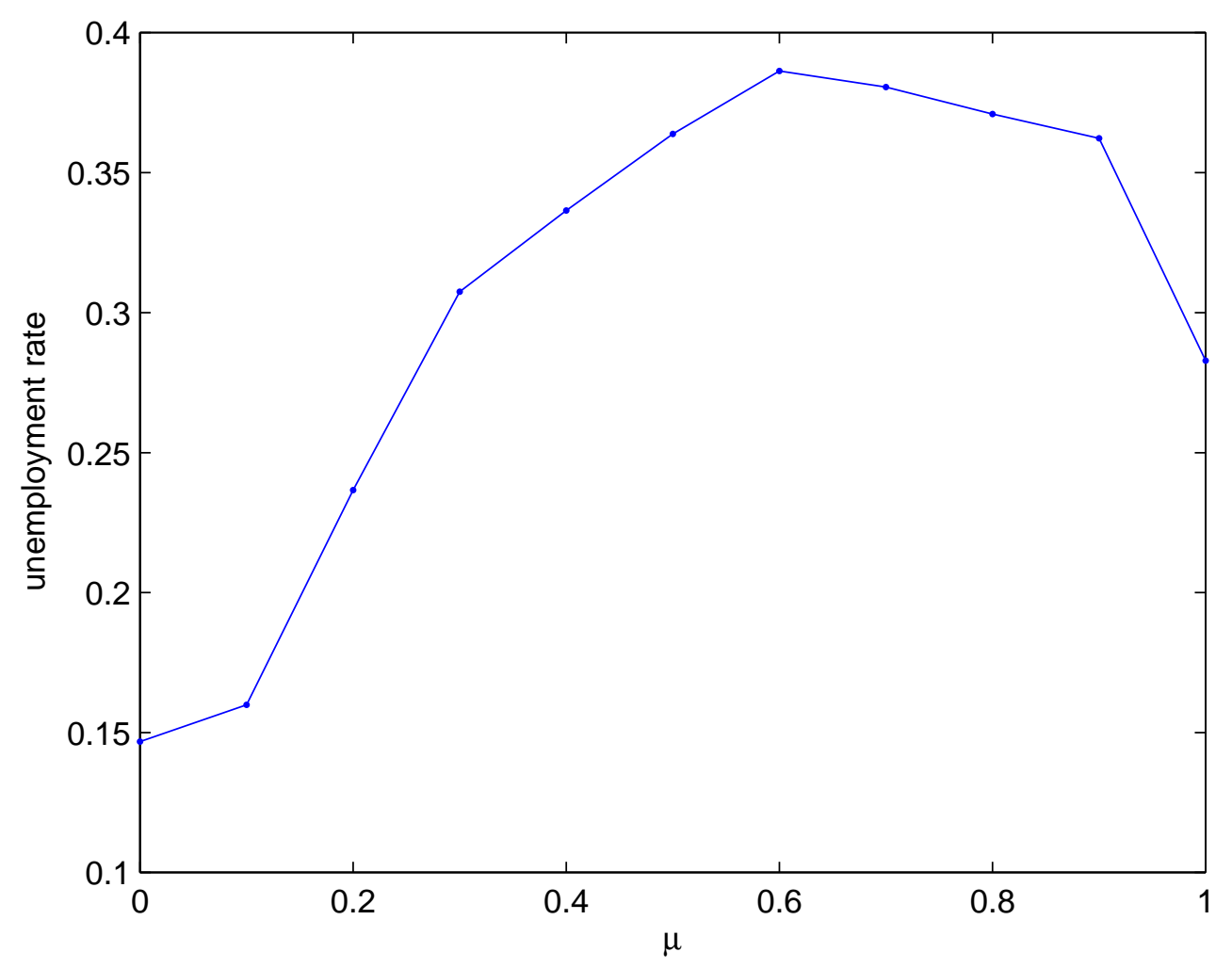


Figure 6: Sensitivity analysis, 100 simulations for each value of the parameter $\mu$ from 0 to 1 by step 0.1 . For each value of $\mu$, we calculated the average value of the unemployment rate for 100 time period representing a stable macroeconomic phase, from $t=101$ to $t=200$.

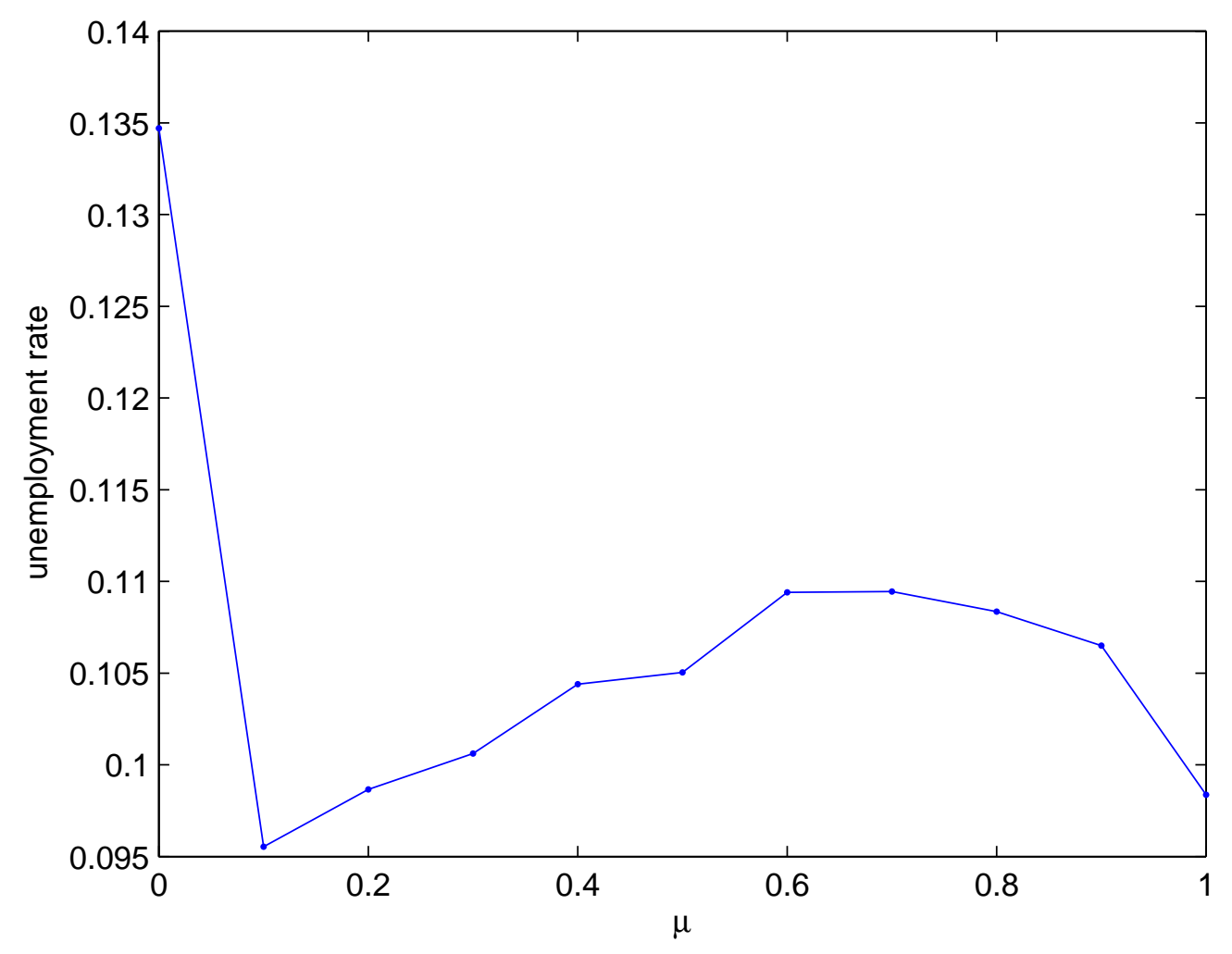


Figure 7: Sensitivity analysis, introducing CC at different time steps, at $t=50,100,200$, and 400. Plots show the time evolution of the average unemployment rate (calculated across 100 MC simulations for each case). CC is introduced at time (i) $t=50$ in the upper-left panel, (ii) $t=100$ in the upper-right panel, (iii) $t=200$ in the bottom-left panel, and (iv) $t=400$ in the bottom-right panel. A vertical line separates the evolution of the unemployment rate before and after the introduction of CC.
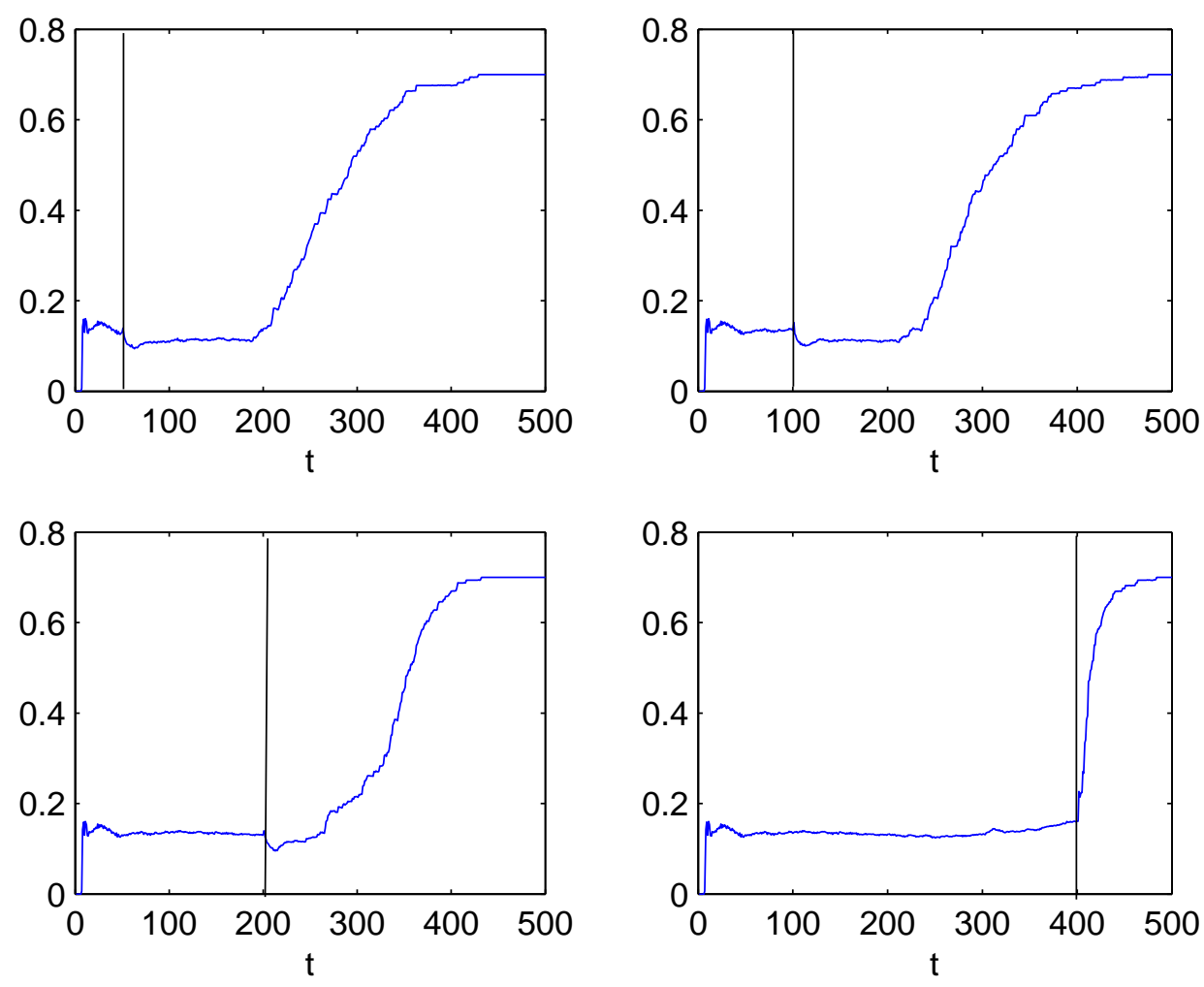

is introduced in the system. In Figure 7, we can find four different timings. Starting with the model without CC at time $t=1$, we introduce CC at time (i) $t=50$ (upper-left panel), (ii) $t=100$ (upper-right panel), (iii) $t=200$ (bottom-left panel), and (iv) $t=400$ (bottomright plot). Let's consider the case (i): after the introduction of $\mathrm{CC}$, there is a decline of the unemployment rate (calculated as the average for each time period across $100 \mathrm{MC}$ simulations) and, after quite a long period, a large crisis develops. A similar story happens in cases (ii) and (iii), even though the period before the crisis is shorter. When CC is introduced too late, for instance, when the system is already on the path towards the crisis, as in case (iv), there is a sudden drop of the unemployment rate and a large crisis erupts.

Finally, observing the time evolution of household wealth (in real terms) in Figure 8, we can see that the introduction of CC, which allows households to finance a level of consumption exceeding their own financial resources, results in a lower average wealth (and a more unequal distribution, as explained before). At the same time, another part of the economy benefits 
Figure 8: Monte Carlo analysis, 100 simulations for each value of the parameter $\mu$ from 0 to 1 by step 0.1 . For each value of $\mu$, we calculated the average real value of households' wealth for 100 time period representing a stable macroeconomic phase, from $t=101$ to $t=200$.

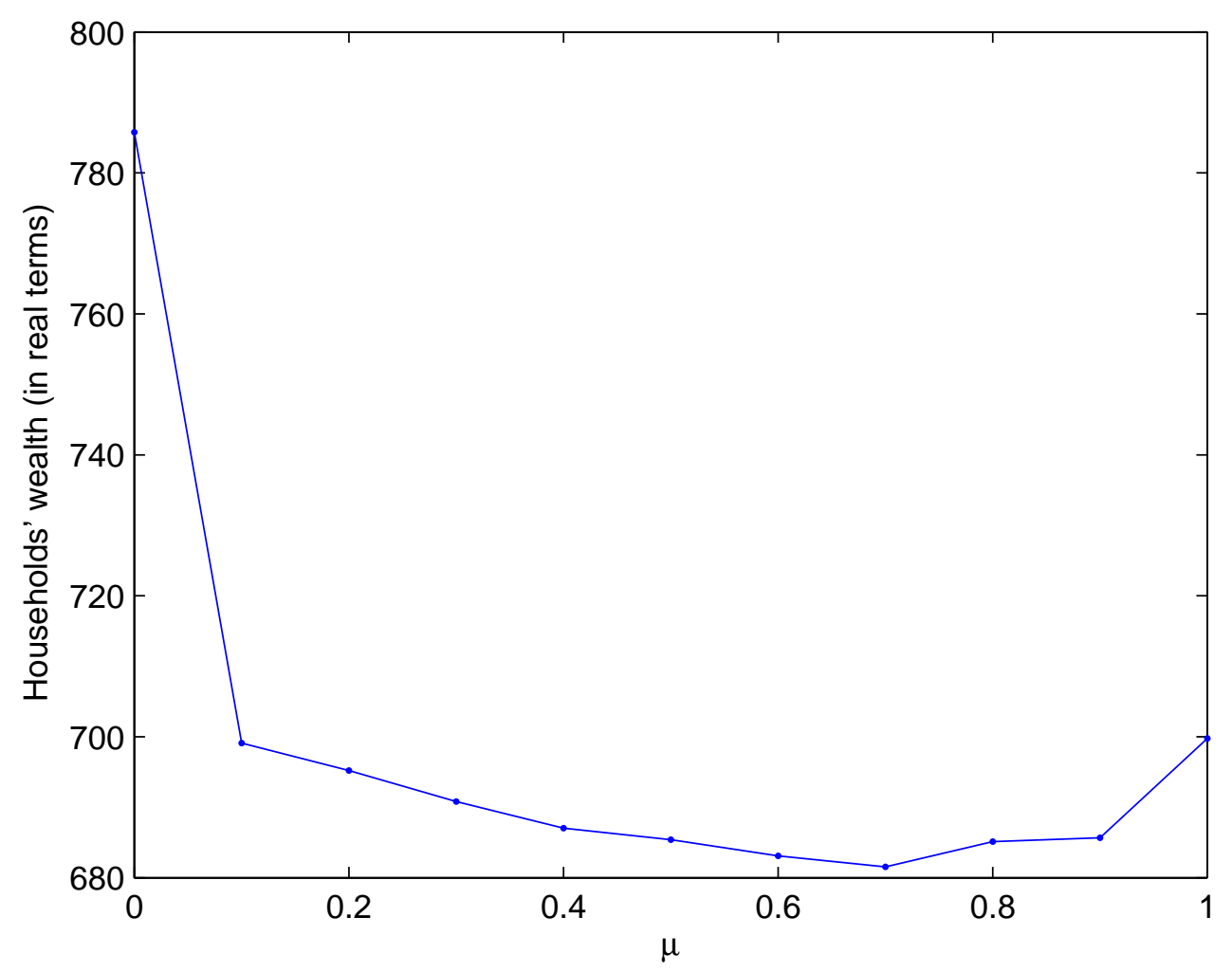

from the introduction of $\mathrm{CC}$, namely the financial system. Indeed, the banks' profit rate is quite higher when $\mathrm{CC}$ is allowed, for all levels of the parameter $\mu$, as shown in Figure 8.

All in all, when households have access to consumer credit, they can enjoy a higher level of consumption that boosts the aggregate demand and decreases unemployment. This positive effect on the macroeconomy can hold for a quite long period of time. But the payment of interests results in lower wealth for households. Then, the rise of inequality and the increase of financial fragility eventually leads to a large and extended crisis. However, while household wealth declines, consumer credit allows banks to expand their activity, thus creating new opportunities for making financial profits. Before the crisis erupts, then, the banks' profit rate is higher than in the "no CC" scenario. Under these circumstances, the decision over the introduction of $\mathrm{CC}$ depends both on the worthiness of allowing households to expand consumption through debt, and on a policy trade-off: is it the case to accelerate the tendency towards the crisis (due to the rise of inequality and financial fragility), thereby, granting a higher profit rate to banks? Obviously, the scope of the analysis and of policy issues is limited by model assumptions and also by the fact that we do not consider any possible 
Figure 9: Monte Carlo analysis, 100 simulations for each value of the parameter $\mu$ from 0 to 1 by step 0.1 . For each value of $\mu$, we calculated the average value of the banks' profit rate for 100 time period representing a stable macroeconomic phase, from $t=101$ to $t=200$.

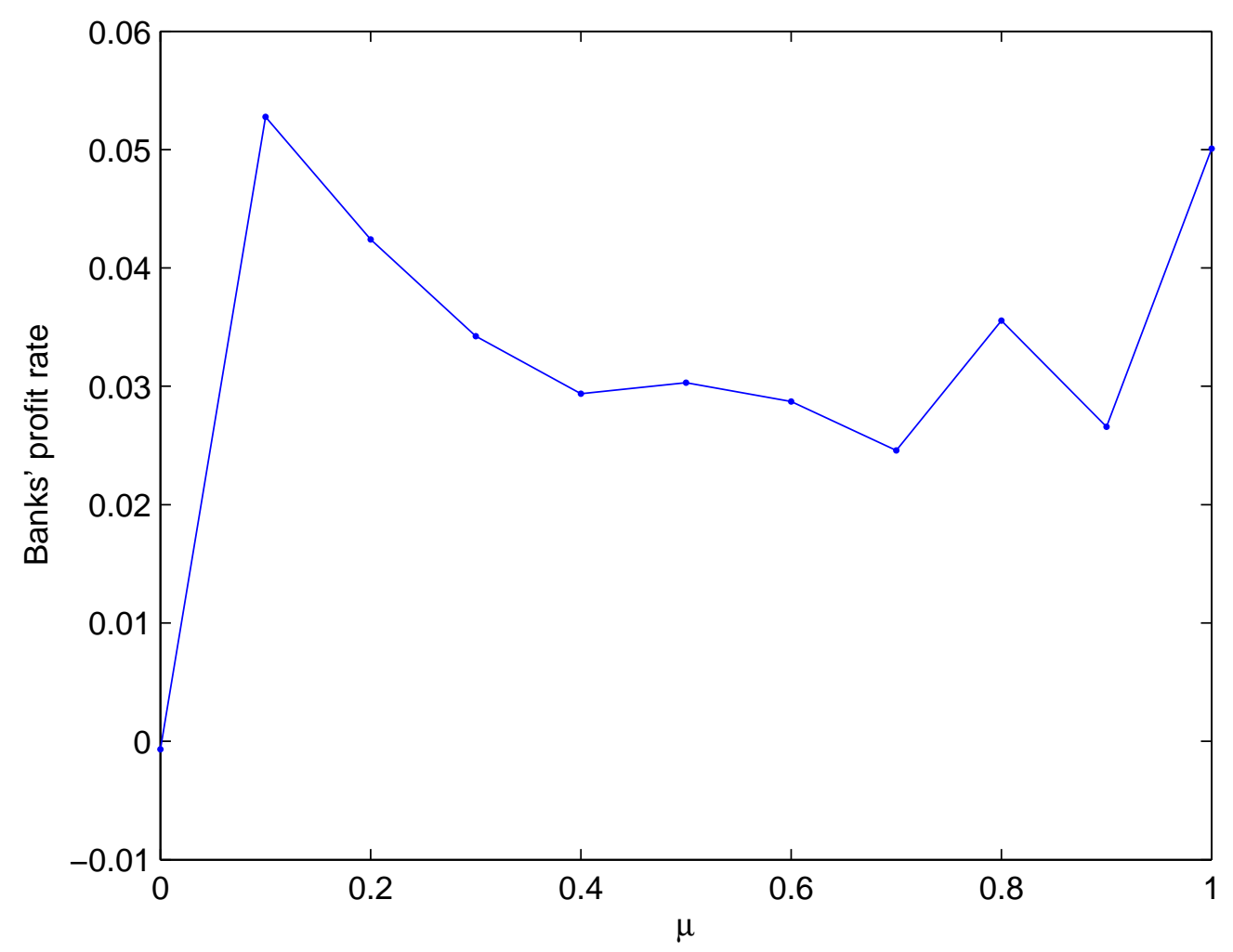

counter-tendency to the decline of firms' profit rate that could restore a stable macroeconomic environment (at least for a while). This could be the subject of future investigations.

\section{Concluding remarks}

We presented an agent-based macroeconomic model to investigate the role of consumer credit on macroeconomic dynamics. The model is composed of heterogeneous agents (households, firms and banks) that interact according to a fully decentralized matching mechanism. The matching protocol is common to all markets (goods, labor, credit, deposits) and represents a best partner choice in a context of imperfect information. The model gives rise to emergent business cycle fluctuations. Moreover, model simulations highlight the fact that even large crises can endogenously emerge when a strong reduction of real wages leads to a fall of the aggregate demand that, in turn, induces firms to decrease production, so enlarging the unemployment rate, in a vicious (positive feedback) circle. In these cases, the system may remain trapped in a large unemployment situation, without the possibility spontaneously to 
recover unless an exogenous intervention occurs.

In this paper, we focused on consumer credit and its impact on macroeconomic evolution. According to van Treeck (2013), to understand the effects of changes in the distribution of permanent income on consumption and saving decisions, the permanent income hypothesis should be abandoned in favor of the old consumption theory proposed by Duesenberry (1943). This theory suggests that the current level of consumption is a function of the maximum consumption reached in a past period, which thus acts as a reference point for households. We considered a very simple case in which household consumption is characterized by "habit formation": they just look at the previous level of consumption. As a future development of our modelling framework, we could improve the implementation of consumption behavior, for instance, by considering that agents can have a longer memory than just one period. Moreover, we could also implement imitation among households when deciding on consumption expenditure or a "keeping up with the Joneses" behavior. ${ }^{18}$

In our artificial macroeconomy, consumer credit can be introduced to allow an expansion of consumption, mitigating the financial constraints for (some) households. The analysis shows that, for a certain period of time, the unemployment rate is lower when households can finance consumption through consumer credit. Indeed, this creates an additional source of aggregate demand. Nevertheless, for successive periods, the unemployment rate tends to rise and the economy evolves towards a large crisis. A similar tendency characterizes the evolution of the unemployment rate for the model without consumer credit, although the economy takes a longer time to evolve towards a large crisis.

On the one hand, consumer credit allows households to buy more goods; this boosts the aggregate demand and results in a lower unemployment rate. On the other hand, as time elapses, the payment of interest on household debt reduces their wealth, which causes a reduction of consumption. As a consequence, households may ask for more consumer credit and, if banks allow households to borrow more, consumption may remain stable or even increase, despite the reduction of household wealth. But this leads to a further reduction of wealth for indebted households that eventually results in higher inequality.

The joint effect of rising inequality and financial fragility when consumer credit is allowed makes happen the crisis earlier than in the baseline scenario. The tendency towards the crisis is related to the dynamics of the productive sector's profit rate. As the profit rate approaches zero, firms tend to decrease the demand of credit to finance production (they prefer to distribute dividends to stakeholders). There is then a process of deleveraging along

\footnotetext{
${ }^{18}$ Although the empirical evidence seems to be against this hypothesis, at least for the US. Indeed, Coibion et al. (2014) investigate whether borrowing patterns on the part of low-, middle-, and high-income households differed depending on local income inequality (where local refers to the geographical dimension, that is, the ZIP code). The authors maintain that local inequality is the most relevant metric for "keeping up with the Joneses". On these bases, they find that banks channel more credit toward lower-income applicants in low-inequality regions than the high-inequality regions.
} 
with the tendency of the economy towards the crisis. However, before the crisis erupts, while household wealth decreases due to the payment of interest on debts, the banks' profit rate is higher than in the baseline model. This means that, under the assumption made and given that we do not consider counter-tendencies to the decline of the real sector's profit rate, the evaluation on the impact of consumer credit is subject to policy considerations. Moreover, the conditions of financial fragility and growing inequality may have an impact on long-run performance through influencing firms' investment decisions, and then capital accumulation, as well as the innovation process based on $R \& D$ expenditure. This is one of the topics we want to investigate in the next future.

Our aim is indeed to improve further our macroeconomic setting in order to develop a useful tool for interpreting the evolution of economic and financial conditions and to analyze policy issues. Then we will work on a demanding research agenda:

- test the consequences of alternative assumptions, such as labor market rigidity, heterogeneous consumption/saving behavior, etc.;

- refine the model with a varying number of actors (firms and banks) and different timings (and frequency) for taking decisions in the various markets;

- extend the model by introducing new markets, for instance, the stock and bond markets, the interbank market, and a market for investment goods;

- extend the model with long-run growth factors (heterogeneous workers' skills, R\&D investments, etc.);

- work on policy experiments (for instance, a progressive tax on wealth that could finance public expenditure to restore macroeconomic stability - and industrial policy to support innovation in an extended model with long-run growth);

Obviously, these items are strictly related. When we extend the model, we will also be able to test for further alternative assumptions and different parameter settings (based on an empirical calibration of the the model), and then we will assess more detailed policy experiments. 


\section{References}

[1] Atkinson A.B., Piketty T., Saez E. (2011), "Top Incomes in the Long Run of History", Journal of Economic Literature, 49(1): 3-71.

[2] Acharya V.V., Gujral I., Kulkarni N., Shin H.S. (2011), "Dividends and Bank Capital in the Financial Crisis of 2007-2009", NBER Working Paper No. 16896, National Bureau of Economic Research.

[3] Barba A., Pivetti M. (2009), "Rising Household Debt: Its Causes and Macroeconomic Implications - A Long Period Analysis", Cambridge Journal of Economics, 33: 113-137.

[4] Brogi M. (2010), "Capital Adequacy and Dividend Policy: Evidence from Italian Banks ", Le banche italiane sono speciali?, G. Bracchi and D. Masciandaro, eds., XV Rapporto annuale della Fondazione Rosselli, available at SSRN: http://ssrn.com/abstract=1707962.

[5] Coibion O., Gorodnichenko Y., Kudlyak M., Mondragon J. (2014), "Does Greater Inequality Lead to More Household Borrowing? New Evidence from Household Data", NBER Working Paper No. 19850, National Bureau of Economic Research.

[6] Delli Gatti D., Gallegati M., Greenwald B., Russo A., Stiglitz J.E. (2010), "The financial accelerator in an evolving credit network", Journal of Economic Dynamics and Control, 34(9): $1627-1650$.

[7] Dosi G., Fagiolo G., Napoletano M., Roventini A. (2012), "Income Distribution, Credit and Fiscal Policies in an Agent-Based Keynesian Model", Journal of Economic Dynamics and Control, 37(8): 1598-1625.

[8] Duesenberry J. (1943), Income, saving and the Theory of Consumer Behaviour, Harvard University Press.

[9] Fazzari S., Cynamon B.Z. (2013), "Inequality and Household Finance during the Consumer Age", INET Research Note, \#023, Institute for New Economic Thinking.

[10] Fisher I. (1933), "The Debt-Deflation Theory of Great Depression", Econometrica, 1(4): 337357.

[11] Fitoussi J.-P., Saraceno F. (2010), "Inequality and macroeconomic performance", Document de travail de l'OFCE No. 2010-13, Centre de recherche en économie de Sciences Po.

[12] Fitoussi J.-P., Stiglitz J.E. (2009), "The Ways Out of the Crisis and the Building of a More Cohesive World", Document de travail de l'OFCE No. 2009-17, Centre de recherche en économie de Sciences Po.

[13] Galbraith J.K. (1954), The Great Crash, Penguin. 
[14] IMF (2007), World Economic Outlook, "Spillovers and Cycles in the Global Economy", chap. 5, International Monetary Fund, April 2007.

[15] Kaldor N. (1955), "Alternative Theories of Distribution", The Review of Economic Studies, 23(2): 83-100.

[16] Kalecki M. (1942), “A Theory of Profits", The Economic Journal, 52(206/207): 258-67.

[17] Kumhof M., Ranciere R. (2010), "Inequality, Leverage and Crises", IMF Working Paper No. 10/268, International Monetary Fund.

[18] Kumhof M., Lebarz C., Ranciere R., Richter A.W., Throckmorton N.A. (2012), "Income Inequality and Current Account Imbalances", IMF Working Paper No. 12/08, International Monetary Fund.

[19] Lazonick W. (2013), "Robots Don’t Destroy Jobs; Rapacious Corporate Executives Do" Huffington Post Blog, http://www.huffingtonpost.com/william-lazonick/robots-dont-destroy-jobs_b_2396465.html

[20] Lazonick W., O’Sullivan M. (2000), "Maximizing shareholder value: a new ideology for corporate governance", Economy and Society 29(1): 13-35.

[21] Minsky H.P. (1982), Can 'It' Happen Again? Essay on Instability and Finance, Sharpe.

[22] OECD (2011), Divided We Stand: Why Inequality Keeps on Rising, The Organisation for Economic Co-operation and Development (OECD).

[23] Palley T.I. (2012), “America's Exhausted Paradigm: Macroeconomic Causes of the Financial Crisis and Great Recession", in: Cynamon B.Z., Fazzari S.M., Setterfield (eds.), After the Great Recession: The Struggle for Economic Recovery and Growth, Cambridge University Press, Chapter 2: 31-60.

[24] Perugini C., Holscher, Collie S., "Inequality, Credit Expansion and Financial Crises", MPRA Paper, 51336, University Library of Munich.

[25] Rajan R. (2010), Fault Lines. How Hidden Fractures Still Threaten the World Economy, Princeton: Princeton University Press.

[26] Riccetti L., Russo A., Gallegati M. (2013), "Leveraged Network-Based Financial Accelerator", Journal of Economic Dynamics and Control, 37(8): 1626-1640.

[27] Riccetti L., Russo A., Gallegati M. (2014), “An Agent-Based Decentralized Matching Macroeconomic Model", Journal of Economic Interaction and Coordination, doi: 10.1007/s11403 $014-0130-8$.

[28] Russo A. (2014), "Elements of Novelty, Known Mechanisms, and the Fundamental Causes of the Recent Crisis“, Journal of Economic Issues, 48(3): 743-764. 
[29] Russo A., Riccetti L., Gallegati M. (2014), "Growing Inequality, Financial Fragility, and Macroeconomic Dynamics: An Agent Based Model", Advances in Social Simulation, Advances in Intelligent Systems and Computing, 229: 167-176, doi: 10.1007/978 - 3-642 - 39829 - 2_15.

[30] Setterfield M. (2012), "Wages, Demand, and US Macroeconomic Travails: Diagnosis and Prognosis", in: Cynamon B.Z., Fazzari S.M., Setterfield (eds.), After the Great Recession: The Struggle for Economic Recovery and Growth, Cambridge University Press, Chapter

[31] Stiglitz J.E. (2010), Freefall: Free Markets, and the Sinking of the World Economy, New York: Norton.

[32] Stockhammer E. (2013), "Rising Inequality as a Root Cause of the Present Crisis", Cambridge Journal of Economics, doi: 10.1093/cje/bet052.

[33] van Treeck T. (2009), "The Macroeconomics of 'Financialisation' and the Deeper Origins of the World Economic Crisis", IMK Working Paper No. 9, IMK, Hans Boeckler Foundation, Macroeconomic Policy Institute.

[34] van Treeck T. (2013), "Did Inequality Cause the US Financial Crisis?", Journal of Economic Surveys, doi: 10.1111/joes.12028.

[35] van Treeck T., Sturn S. (2012), "Income Inequality as a Cause of the Great Recession? A Survey of Current Debates", ILO Working Paper, Condition of Work and Employment Series, No. 39, International Labour Organization.

[36] Wade R. (2009), "The global slump. Deeper causes and harder lessons". Challenge, 52(5): 5-24. 